\title{
La Revolución mexicana $y$ los inicios de la organización empresarial (1917-1918)
}

Nicolás Cárdenas García

\section{Introducción}

La Revolución mexicana fue un acontecimiento decisivo para la configuración de las características básicas del modelo de desarrollo nacional, tanto en lo económico como en lo político. Fruto de ella son la modernización del capitalismo, la estabilidad política de un régimen marcadamente autoritario y el papel predominante del Estado en la sociedad.

A partir del hecho de que los dirigentes constitucionalistas y los diputados al Congreso constituyente provenían en su mayoría de los sectores medios, existió la posibilidad de conformar un programa y una ideologia que dieran sustento al desarrollo nacional al mismo tiempo que homogeneizaran los intereses de las fracciones de la clase dominante, y contuvieran reformas sociales que vinculasen a las masas populares con dicho proyecto. Asimismo, esto explica la aparente autonomía con que el Estado empezó a actuar, respecto a la burguesía y el proletariado, clases fundamentales de la sociedad. ${ }^{1}$

Pero si por un lado la naciente elite política pudo muy pronto incorporar a los trabajadores a su proyecto, a través del pacto entre la Casa del Obrero Mundial y el constitucionalismo primero, y después con la alianza CROM- sonorenses, por el otro le fue muy difícil llegar a una colaboración y entendimiento con la clase patronal. El presente trabajo se ocupa de ilustrar, por medio del estudio de los primeros congresos nacionales de comerciantes e industriales, la actitud de los empresarios frente a la Revolución ante una invitación del Estado a participar en la reconstrucción nacional. Para estudiar estos aspectos debemos empezar por el hecho ya demostrado de que por las décadas de 1920 y 1930 , la clase dominante del porfirismo prácticamente no sufrió alteraciones, tanto en lo que respecta al grupo de terratenientes, como, y sobre todo, en aquella fracción dedicada a la industria y al comercio. Ciertamente algunos de ellos sufrieron los efectos del conflicto armado y en general la producción en todos los renglones, exceptuando el petróleo y el henequén, descendió entre 1910 y 1917, logrando en la mayoría de los casos alcanzar los niveles que tuvo desde 1910 hasta 1925 , pero también es cierto que los costos de esta crisis no recayeron en los industriales, sino en los trabajadores y campesinos. La depreciación de la moneda constitucionalista, la inflación y la escasez de alimentos fueron factores que aprovecharon los banqueros, comerciantes e industriales para especular y obtener grandes ganancias. A ello se agrega la protección que.

\footnotetext{
"Véase Arnaldo Córdova, "México, Revolución Burguesa y Política de Masas", en varios, Interpretaciones de la Revolución Mexicana, México, UNAM-Nueva Imagen, 5 a. ed., 1981, p. 55-89.
} 
el gobierno brindó a diversas empresas para que continuaran su producción. ${ }^{2}$

El reformismo social en el terreno legislativo se había traducido en la reivindicación del territorio nacional como propiedad de la nación - personificada en el Ejecutivo-, en las concesiones a los obreros y campesinos y en el papel arbitral del Estado en los conflictos de clase. Sin embargo, todo ello se hacía con el propósito de que ese Estado auspiciara y promoviera el desarrollo de una clase de propietarios privados nacionales dinámicos y eficaces. ${ }^{3}$

Finalmente, había una razón de enorme peso para que el Estado se preocupara de la promoción del desarrollo económico. La burguesía nacional era todavía una clase débil y en buena medida se encontraba subordinada al capital transnacional. Además, puesto que los sectores más dinámicos de la economía estuvieron ocupados durante el porfirismo por el capital extranjero, su área de influencia se limitó a la industria de la transformación, al comercio y a la producción agrícola, ${ }^{4}$ lo cual nos ayuda a comprender el interés del Estado por alentar su organización.

La actitud de los empresarios de 1911 a 1917 parece haber sido la de esperar los resultados de la conmoción social. Aunque una parte emigró al extranjero, otros simplemente

respondieron a las presiones que la misma guerra les imponía, disminuyendo la producción y cerrando las fábricas si los obreros se incorporaban a filas o cuando las operaciones militares hacian imposible el suministro de materia prima. ${ }^{5}$

Una vez restablecido el orden constitucional dentro de los lineamientos de la nueva constitución, el gobierno carrancista se propuso la difícil tarea de reconstruir la economía nacional. Ello no podía lograrse sin el concurso de la naciente burguesía nacional y del capital extranjero que tan profusamente había sido invertido en el país en las décadas anteriores. Pero los términos en que se daba inicio a esas negociaciones en 1917 no podían ser peores. Por un lado estaba la Constitución, cuyos artículos de contenido social afectaban profundamente los intereses de empresarios habituados a un régimen de privilegios. Por otro, estaban las amenazas de incautación con que el régimen respondió a la actividad contrarrevolucionaria. Tal vez un único aliciente para los empresarios era la notoria dureza con que el presidente Carranza daba res-

\footnotetext{
2 Véase Nicolás Cárdenas García, De Sonora a Palacio Nacional: el conflicto CarranzaObregón, Tesis de licenciatura, México, ENEP Acatlán-UNAM, 1984, p. 22-35; John Nomack, "La Economía en la Revolución (1910-1920). Historiografía y análisis", en $\mathrm{Ne}$ $x o s$, Año 1, núm. 11, noviembré de 1978, p. 3-8; y Douglas W. Richmond, "El Nacionalismo de Carranza y los cambios socioeconómicos 1915-1920", en Historia Mexicana, vol. XXVI, julio-septiembre 1976, núm. 1.

${ }^{3}$ En José Maria Calderón, Génesis del Presidencialismo en México, se encuentra una excelente discusión al respecto. México, Eds. El Caballilto, 3a. ed., 1980.

4 Véase Juan Pablo Arroyo, "Porfirio Díaz y el Imperialismo" En Historia y Sociedad, núm. 24, 1981, p. 51-69. José Luis Ceceña, México en la Órbita Imperial, México, Eds. El Caballito, 13a ed., 1981, p. 49-101; y Fernando Rosenzweig, "El desarrollo económico de México de 1888 a 1911 ", en El Trimestre Económico, julio-septiembre de 1965, vol. XXII, múm. 127, p. 405-454.

${ }_{3}$ Maria Cristina Puga Espinoza, Los industriales y la revolución Méxicana, Tesis Profesional de Licenciatura, México, FCP y S UNAM, 1975, p. 10.
} 
puesta a las demandas de los trabajadores, ejemplificada en la huelga general del Distrito Federal de 1916.

El gobierno dio el primer paso con la creación de una secretaría de estado encargada de estos asuntos: la Secretaría de Industria, Comercio y Trabajo - aunque esta última palabra se le añadió más tarde-, que inició sus labores el 5 de abril de 1917. El titular de esta nueva dependencia del ejecutivo, Alberto J. Pani, se puso de inmediato a la tarea de negociar con los empresarios para tratar de obtener su colaboración en materia de desarrollo económico.

Puede apreciarse el resultado si consideramos que, de acuerdo a las cifras oficiales, en 1919 había en el país 3804 establecimientos industriales, con un capital de aproximadamente 250 millones de pesos y que en ellas laboraban alrededor de 85000 obreros. $^{6}$

\section{El gobierno frente a los empresarios}

Las ideas centrales de la política del gobierno frente a los empresarios parecen haber sido las siguientes:

En primer lugar, la preocupación por fomentar la pequeña industria, más que por considerarla productiva, porque por medio de ella se podía formar una clase media. Esto es similar a la preocupación que en el Congreso constituyente se expresó por la constitución de la pequeña propiedad agrícola. Se buscaba influir en la composición social del país, puesto que era fácilmente reconocible el abismo que mediaba entre las clases dominantes y los trabajadores. El presidente planeaba con mucha claridad este objetivo de su primer informe, (10. de septiembre de 1917); decía en esa ocasión que el fomento a la pequeña industria

Constituiría el factor más importante para la formación de una clase media autónoma que, siendo al mismo tiempo capitalista y trabajadora, tienda a disminuir conflictos entre las demás clases sociales y contribuya a corregir los defectos de constitución económica de que adolece el país. ${ }^{7}$

De manera que el objetivo era, si no cancelar, sí amortiguar la lucha de clases, no sólo mediante los mecanismos jurídicos ya establecidos constitucionalmente, sino también por medio de modificaciones estructurales.

En segundo término, se trataba de promover la organización de las clases fundamentales, para tener interlocutores que representaran sus intereses a nivel nacional, entre los cuales desempeñaría el naciente Estado el papel de árbitro que le asignaba la Constitución.

${ }^{6}$ Venustiano, Carranza, Tercer Informe de Gobierno, 1 de septiembre de 1919, en Los Presidentes de México ante la Nación, t. III, p. 560. Estos datos tomaban en consideración las ciudades de más de tres mil habitantes de veinte estados de la República. A pesar de no incluir a Sonora y Chihuahua, la clasificación de las mismas hace pensar que las tendencias no sufririan variaciones.

Industria alimenticia 698

Industria textil 213

Industria minera 614

Industria eléctrica 40

Industrias diversas 2245

7 Venustiano Carranza, Primer informe de Gobierno, 1 de septiembre de 1917, en Los Presidentes de México ante la Nación, t. III, p. 224. 
El ingeniero Alberto J. Pani, artífice de esta política, durante el primer año del gobierno de Carranza en que ocupó la cartera de Industria, Comercio y Trabajo desarrolló intensa actividad para ponerla en práctica. Su influencia ante el presidente era tal que en ese corto lapso se llevaron a cabo los congresos nacionales de comerciantes e industriales, pero no puede afirmarse que Carranza tuviera las mismas convicciones. De hecho parece plausible afirmar que su acendrado liberalismo chocaba con este proyecto corporativista de su secretario. En efecto, en cuanto se presentó una ocasión propicia, al normalizarse las relaciones con las naciones europeas, Pani fue designado embajador de México en Francia. Arguyó después que la razón de ese nombramiento fue que era el único miembro del gabinete que se había mostrado "ostensiblemente simpatizador de las potencias Aliadas y Asociadas" y que tal designación se hizo a sugerencia del encargado de negocios de Francia en México. Esa versión es difícil de aceptar. En la práctica, después de su salida el proyecto antes mencionado no tuvo más avances. ${ }^{8}$

Además de esa razón de carácter ideológico, debe haber contribuido a su separación del gabinete el que los congresos no hayan rendido los frutos esperados. No se pudo lograr un acercamiento entre Estado y empresarios, y mucho menos una colaboración para la reconstrucción nacional. Tenian que ocurrir otras cosas para que ambas entidades superaran la desconfianza inicial y entendieran que perseguian propósitos semejantes. Cuando ocurrió, en los periodos presidenciales de Obregón y Calles, Pani volvió a integrarse a la administración pública. Era el inicio de la industrialización, de la intervención del Estado en el proceso de acumulación de capital e, incluso, en la promoción de una burguesia nacional.

\section{El Congreso Nacional de Comerciantes}

La Secretaría de Industria, Comercio y Trabajo convocó al Primer Congreso Nacional de Comerciantes, el cual sesionó del 12 de julio al 4 de agosto de 1917, con la asistencia de 130 delegados de todo el país, representantes de treinta cámaras nacionales de comercio, cinco cámaras de comercio extranjeras, cinco sociedades o cámaras mixtas (industriales, agrícolas y comerciales), dos sociedades para ayuda del comercio, tres cámaras agrícolas, cuarenta comercios que no se habían organizado en cámaras, doce ayuntamientos, una sociedad mutualista, una escuela comercial, la Universidad Popular, una asociación de contadores titulados y un colegio de corredores. El temario que este congreso debía abordar, elaborado por la Secretaria, era el siguiente:

a) moralización del comercio,

b) medidas que conviene dictar para hacer frente al posible encarecimiento de los artículos de primera necesidad,

c) organización colectiva de las cámaras de comercio de la República para los fines de ayuda mutua, de conveniencia pública y de representación ante el gobierno federal, y

d) medidas que deben ponerse en práctica para desarrollar nuestro comercio interior y exterior. ${ }^{9}$

8 Alberto J. Pani, Mi contribución al nuevo régimen, 1910-1933, México, Ed. Cultura, 1936, p. 250.

9 Alberto J. Pani, Mi contribución al nuevo régimen, 1910-1933, Op. cit, p. 246; y Venustiano Carranza, Primer Informe de Gobierno, en Los Presidentes de México ante la Nación, t. III, p. 225. 
La realización del evento fue calificada en el informe del presidente al Congreso de la Unión como el acto más importante del Departamento de Comercio, ya que marcaba

por vez primera, en nuestra historia, la iniciación de una elevada política democrática o de cooperación efectiva entre el gobierno y el pueblo para el estudio y resolución de los problemas trascendentales del país... ${ }^{10}$

En el discurso que pronunció en la sesión inaugural del Congreso, Pani afirmó que a través del mismo los comerciantes de todo el país se incorporaban a la Revolución."

En seguida señaló que la labor reconstructiva constaba en realidad de dos partes; la restauración de las sumas perdidas de bienestar material y de moralidad y la curación de la grave enfermedad de constitución económica de que adolecia nuestra sociedad, reiterando que el gobierno queria la colaboración de los comerciantes para la aplicación de tal proyecto. ${ }^{12}$

Además, el ministro aprovechó la oportunidad para extenderse en la tesis de la amortiguación de los conflictos sociales.

Una sociedad - decía - compuesta, principalmente, de algunos privilegiados y una gran masa de proletarios, y en que los primeros pueden acumular riquezas fabulosas con facilidad y rapidez excesivas y fuera del trabajo y del ahorro personal o del trabajo y ahorro de sus ascendientes, y los segundos se encuentran en la imposibilidad material de ascender a la categoría de propietarios, está llamada a transformarse en campo exclusivo de parasitismo y de indigencia y a desaparecer; tras una agonía más o menos larga, pero sí muy agitada y dolorosa.

Se trata pues, de un estado patológico grave, revelado por la casi continuidad de brutales luchas de clases, que es urgente curar. Precisa para esto, una cooperación de esfuerzos extraordinarios tendientes a la regeneración moral, intelectual y económica del proletariado y a la creación y fomento de una clase media autónoma.

Reveló en el mismo discurso las fuentes que nutrían ese pensamiento, citando al diputado belga Cooreman, a propósito de la importancia de la clase media:

Se interesa todo el mundo en el mejoramiento de la condición moral y material de la clase obrera y todo el mundo tiene razón... Pero la conservación, la prosperidad de la clase media es causa no menos justa, y exige el interés público que no peligre su existencia. Importa al equilibrio social que las diferencias entre la clase capitalista y la clase obrera las armonice la clase media, caracterizada por la reunión, en las mismas manos, del capital y del trabajo. Es indispensable para el reinado de la armonia en la sociedad, que la escala tenga entre su más alto y su más bajo escalón una serie de grados intermedios

10 Ibid.

"Alberto J. Pani, En camino hacia la democracia, México, Depto. de Aprovisionamientos Generales, Dirección de Talleres Gráficos, 1918, p. 29.

12 Alberto J. Pani, En camino hacia la democracia, op. cit., p. 38-40 
que reúnan los extremos por gradaciones más numerosas que espaciadas. ${ }^{13}$

Finalmente, expresó su convencimiento de que ése era el camino que habia abierto la Revolución:

La tendencia revolucionaria no está orientada hacia la utópica nivelación socialista; su ideal social es aquel que permita a cada hombre obtener, de la suma de bienestar conquistado por la colectividad, la parte proporcional a su aportación personal de trabajo, de inteligencia y de economía.

Sin embargo, la buena disposición del gobierno no pareció merecer reciprocidad por parte de los comerciantes, ya que como hemos señalado, el alza de los precios y la especulación fueron características del periodo. Por lo demás, los comerciantes tenían el propósito de fortalecerse como sector de clase, ya que entre las iniciativas más importantes surgidas en el congreso destacó la de crear un banco comercial mexicano y la de impulsar ante el gobierno la apertura de nuevas vías de comunicación que les permitieran tener más mercados a su alcance. ${ }^{14}$

En cuanto a la resolución del problema del suministro de alimentos básicos que, como se mencionó anteriormente, era una de las preocupaciones fundamentales del gobierno, en el Congreso se creó un Comité de Artículos de Primera necesidad con el propósito de importar maíz de los Estados Unidos. El gobierno mexicano subsidió tal adquisición con la cantidad de 600000 dólares, poco menos de la mitad del monto total. ${ }^{15}$

El objetivo de promover la organización de los comerciantes sí se alcanzó, ya que la asamblea acordó que cada año se nombraría un comité ejecutivo con residencia en la capital, que representaría a la nueva organización. De esa manera, en una nueva asamblea, el 3 de noviembre de 1917 se constituyó la Confederación Nacional de Cámaras de Comercio. ${ }^{16}$

El gobierno, fiel a su propósito de mejorar sus relaciones con este sector de la sociedad, atendió algunas de sus proposiciones, como la de montar una exposición comercial permanente, acreditar agencias comerciales en los Estados Unidos y restructurar la escuela de comercio. ${ }^{17}$

Los logros de este primer acercamiento con los empresarios parecían alentadores, pero más bien significó una importante experiencia previa a la negociación con los intereses industriales que habian sido más afectados por el movimiento revolucionario, en particular por la Constitución de 1917.

\section{El Primer Congreso Nacional de Industriales}

A petición del Centro Industrial Mexicano, con sede en Puebla, ıa Secretaría de Comercio, Industria y Trabajo envió el 25 de septiembre una

13 Ibid., p. 42-43.

if Venustiano Carranza, Primer Informe de Gobierno, 1 de septiembre de 1917, en Los Presidentes de México ante la Nación.... t. III, p. 225.

is Venustiano Carranza, Segundo informe de Gobierno, en Los Presidentes... t. III, p. 282-283.

${ }^{16}$ Carlos Arriola, "Las organizaciones empresariales contemporáneas", En Lecturas de política mexicana, México, El Colegio de México, 1981, p. 325.

17 Venustiano Carranza. Segundo y Tercer informes de Gobierno, 1 de septiembre de 
nota a la Comisión Permanente del Primer Congreso Nacional de Comerciantes, en que le encargaba la realización de otro evento similar, pero que reuniría a los representantes de los industriales que operaban en el país.

En ese mensaje se señalaba que la participación de cada estado no podía exceder de seis delegados de todas las ramas industriales, extractivas o manufactureras. La proporción en que cada una estaría representada se dejó al criterio de la corporación convocante en cada entidad. Eso hizo que la representación de los estados dependiera del poder que cada sector tuviera en el mismo. La convocatoria podía partir de las cámaras industriales o mineras, de las de comercio en caso de no existir las anteriores o bien de la comisión permanente, en caso de existir dos o más cámaras de comercio.

Por otra parte, señalaba enfáticamente que el congreso trataria exclusivamente las siguientes cuestiones:

I. Organización de Cámaras en toda la República, confederación de las mismas para fines de ayuda mutua, y establecimiento en la ciudad de México de los órganos que sirvan de comunicación entre las diversas ramas de la Industria y el Gobierno.

II. Medios de fomentar el desarrollo industrial del pais.

III. Legislación en sus relaciones con las industrias. ${ }^{18}$

Una observación necesaria es que el gobierno reconocía el mayor peso que tenían los industriales en la vida económica del país, puesto que incluía en el temario una cuestión tan delicada y controvertible como el análisis de la legislación, cosa que no permitió en el caso de los comerciantes.

Eduardo Mestre, Secretario de la Comisión Permanente del Congreso de Comerciantes, responde afirmativamente al día siguiente y la convocatoria se expide el 27 de septiembre en los términos fijados por el Secretario Pani. Entre las facilidades otorgadas a los representantes industriales estaba la de proporcionarles pases de ferrocarril de ida y vuelta. ${ }^{19}$

Como informaba el propio Mestre al clausurar el congreso, estuvieron presentes 112 delegados de 24 estados, del Distrito Federal y del territorio de Baja California. Las entidades sin representación fueron, según reconocía en su discurso, aquellas esencialmente agrícolas, donde la industria prácticamente no existía, esto es Chiapas, Morelos, Nayarit, Oaxaca, Quintana Roo y Campeche, aunque en este caso fue designado un delegado que no se presentó. La aserción de Mestre era cor recta, salvo en el caso de Morelos, donde la industria existía pero estaba paralizada por la acción de los zapatistas. Un rasgo importante que reconocía en esa intervención era que, como podía esperarse por los términos de la convocatoria, las ramas con menor presencia fueron las de pequeña industria e industrias varias, lo cual provocó que se reu-

1918 y 1 de septiembre de 1919, en Los Presidentes de México ante la Nación, ..., t. III, p. 283 y 360-361; Alberto J. Pani, En camino hacia la democracia, op. cit., p. 141.

${ }^{18}$ Reseña y Memorias del Primer Congreso Nacional de Industriales reunido en la Ciudad de México bajo el patrocinio de la Secretaría de Industria, Comercio y Trabajo. México, Departamento de Aprovisionamientos Generales, Dirección de Talleres Gráficos, 1918, p. 11-12. En lo sucesivo se citará como Reseña y Memorias...

19 Reseña y Memorias..., p. 13-14. 
nieran ambas en una sola sección de discusiones. Por lo tanto funcionaron durante el evento las cuatro secciones siguientes:

Sección Minera 34 miembros.

Sección Petrolera 15 miembros.

Sección Textil 28 miembros.

Sección de Pequeña Industria e industrias varias 33 miembros. $^{20}$

Los puestos clave de Presidente y Secretario del Congreso y de la Comisión Permanente que se eligió al final, recayeron respectivamente en Alberto Henckel y Eduardo Mestre, quienes ocupaban esas mismas posiciones en la Comisión Permanente de Comerciantes. En tanto que representaban a las industrias varias y a los textileros de Puebla, puede presumirse que en un primer momento estas ramas predominaron en el Congreso, aunque se tuvo buen cuidado de incluir entre los 15 vocales de la Comisión Permanente a tres representantes de los mineros y a otros tantos de los petroleros. ${ }^{21}$ Esto también indica que se operaba un proceso de integración entre capitales industriales y comerciales.

Sin embargo, esto no quiere decir que en los debates internos careciera de importancia la posición de los petroleros, ya que de la-memoria del congreso la cuestión petrolera ocupa alrededor del 22 por ciento.

El Congreso se inauguró el 17 de noviembre de 1917. En esa oportunidad el secretario Alberto J. Pani se explayó en la exposición de lo que llamó "Política Democrática Industrial".

La base de esta política estaba en que el gobierno, lejos de pretender abusar del poder que le dio la Revolución, llamaba a las clases activas de la sociedad a participar en las funciones de la administración pública. Y agregó con énfasis:

Nadie se atreverá a negar que semejantes tendencias democratizadoras; llevadas, si posible fuera, hasta la dilución completa del Gobierno en la masa social, tendrían que resolverse necesariamente, en la perfecta coordinación de todos los intereses nacionales.

El objetivo que se proponía el régimen era, reiteraba, corregir la defectuosa constitución económica del país, acercando los extremos enojosos que existían en su seno "con la moralización de los de arriba, el puente de una clase media autónoma y el mejoramiento de la condición material de los de abajo." Para lograr ese propósito era necesario, según Pani:

La repartición de la propiedad raíz entre el mayor número posible de gentes y el fomento de la pequeña industria, como factores preponderantes, casi decisivos, en la formación de una clase media autónoma, contribuirían, pues, de manera muy poderosa, a corregir los defectos de que adolece nuestra constitución económica y a evitar, en el porvenir, los padecimientos consuetudinarios de la Patria.

En lo que toca al primer aspecto, es decir al mejoramiento de la condición material del proletariado, el camino para lograrlo no estaba en cuestiones legales u organizativas, sino en "provocar una fuerte de-

20 Ibid., p. 80-82.

${ }^{21}$ Ibid., p. 27 
manda de trabajo, esto es, en determinar, con esfuerzos eficientes, el desarrollo máximo - compatible con nuestras condiciones- de la pequeña y la grande industria".

En seguida, el ministro hacia una defensa de la libre concurrencia, argumentando que la protección y privilegio de "industrias exóticas que sólo puedan vivir dentro de la incubadora de la protección oficial" frenarian el progreso material, además que su secuela sería el alza de precios y el malestar general por favorecer el gobierno a unos cuantos. El mismo Pani sintetizaba sus planteamientos:

Puede decirse, pues, en pocas palabras, que la captación, extracción y transformación de los productos naturales de nuestro suelo y la libre concurrencia nacional e internacional, son los dos términos principales de la fórmula de nuestra política industrial.

La exposición del ministro no podía eludir el espinoso problema de las relaciones óbrero-patronales, de manera que lo abordó señalando, de partida, que sus conflictos no deben resolverse a favor de uno u otro, como ocurría en los países donde gobernaban oligarquías o democracias desorganizadas o demagógicas. Por el contrario:

En una democracia bien organizada no puede, no debe ocurrir ninguna de estas dos cosas. Si la producción industrial o servicio que responde a necesidades colectivas imperiosas, requiere, como condición indispensable, la conjunción de los factores llamados capital y trabajo, es obvio que las obligaciones supremas de protección y garantía del Estado - representante y guardian de los intereses comunes del pueblo- deban tender constantemente a conservar toda la fuerza de producción o de funcionamiento de dichá dualidad, es decir, a evitar que ésta se perturbe, desequilibre o destruya por el favor oficial hacia uno sólo de sus dos factores constitutivos. De aquí se deduce que ni el patrón ni la masa obrera - queriendo significar con esta última expresión o la totalidad de los operarios o la parte de ella que pueda influir sensiblemente en la producción o servicio público de que se trate - tienen el derecho de paralizar o reducir esta producción o servicio, de un modo injustificado y con perjuicio apreciable para la comunidad, y que, por lo tanto, en los casos relativos de paralización o reducción de la actividad industrial, el Estado tiene el deber imprescindible de intervenir, en la forma que mejor proceda, para impedir o reparar la lesión de los intereses generales. ${ }^{22}$

En esa misma ocasión el presidente del Congreso, Henckel, elogió el desinterés que los empresarios mostraron, abandonando sus hogares y negocios, para trabajar largos dias "en bien de los intereses generales de la industria patria". De inmediato pasó a señalar que la libertad era condición necesaria para el adelanto industrial y para llevar a cabo nuevas inversiones.

En cuanto a las relaciones obrero-patronales, coincidió con el ministro en cuanto a que debían ser armónicas y apuntó que el Congreso debía abocarse a la búsqueda de los caminos que condujeran a ese resultado.

22 Alberto J. Pani, En camino hacia la democracia, op. cit., p. 82-96. 
Propondréis asimismo - dijo a los delegados - bases justas y prudentes que establezcan la armonía que debe reinar en las relaciones de los industriales con los obreros; y cuya falta obedece tal vez a poca condescendencia de unos y excesivas pretensiones de los otros. Esta discordia perturba y suspende casi diariamente la marcha de nuestra industria y la amenaza con próximos conflictos, más graves todavía, que urge prevenir. Verdad es que, para ello, seria insuficiente toda nuestra buena voluntad si los obreros no pusieran a su turno toda la buena suya; pero alguna de las partes ha de tomar la iniciativa en esta reconciliación venturosa, que hará que industriales y obreros se estimen y respeten reciprocamente, y se reconozcan, sin condenables ruindades, sus respectivos derechos; no hay otra manera de cumplir con el mandato eterno de la justicia, que nos obliga a cada uno a reconocer lo que es suyo. El capital y el trabajo son en absoluto igualmente necesarios para la producción de las riquezas, del propio modo que el oxígeno y el hidrógeno para dar origen al agua; por tanto, las riquezas que se produzcan tienen que distribuirse entre los capitalistas y los trabajadores; ni unos ni otros están facultados para exigir preferencias que lastiman o exasperan. Resultaria tan inicuo negar al obrero el salario a que tiene derecho por su trabajo personal y que le es indispensable para vivir, como arrebatar al industrial la utilidad que debe obtener por el capital que aporta y aventura y que es también su trabajo anterior acumulado, sin la cual tampoco podría subsistir. De acuerdo con esto, os ha dicho hace un instante el señor secretario de Industria y Comercio, que para el supremo gobierno será una obligación fundamental tender constantemente a conservar toda su fuerza de producción o de funcionamiento al capital y al trabajo, evitando perturbaciones, desequilibrios o aniquilamientos causados por el favor oficial hacia uno solo de los factores constitutivos: así lo exige la ley de igualdad, base primera de las sociedades democráticas modernas. ${ }^{23}$

Los discursos inaugurales presagiaban que el Congreso no se apartaría mucho de las líneas que el gobierno deseaba que siguiera, pero en las discusiones sobre las leyes en su relación con las industrias fue evidente que esa apreciación era incorrecta, puesto que los artículos 27 y 123 recibieron fuertes críticas de los empresarios. El primero, por parte de los petroleros y mineros, y el 123 por los representantes de la industria manufacturera.

Dictamen sobre el artículo 27. Este dictamen fue el más largo de cuantos hubo en el Congreso; en la memoria ocupa 67 páginas. Lo elaboró una comisión integrada por tres representantes de compañías petroleras, dos de mineras y uno de los comerciantes de Aguascalientes.

En principio, estos industriales señalaban su desacuerdo con la lucha armada recién concluida, ya que, según su punto de vista, los medios revolucionarios no eran adecuados para escribir las leyes fundamentales de un país. A pesar de ello, advertían que llegaban al texto constitucional sin rencor ni odio politicos, sino bajo la consideración de trabajar por el bien nacional y con el deseo de coadyuvar con el gobierno en la reconstrucción del país. ${ }^{24}$

${ }^{23}$ Reseña y Memorias..., p. 49-50.

${ }^{24}$ Ibid., p. 272-273. 
Iniciaban el estudio con un pormenorizado alegato acerca del carácter republicano, democrático y federal que se había adoptado para nuestro país como forma de gobierno, haciendo hincapié en las fuentes de que se habia nutrido tal concepción - constituciones francesa, norteamericana, de Cádiz - y en los textos constitucionales que precedieron al de 1917. Esta forma de gobierno no tenía otro objeto, señalaban, que preservar los derechos del hombre a la libertad, la vida y la propiedad individual.

En resumen, la finalidad de la Ley Suprema del país es la protección más eficaz, más segura y más firme de los derechos del hombre, libertad, vida, propiedad, contra las agresiones de los mismos Poderes Públicos, de los criminales y de los amagos internacionales.

Fuera de esto, una Constitución republicana no tiene sentido ni razón de ser. ${ }^{25}$

Y en caso de que el gobierno desconociera tales derechos, desconocería su propia existencia y caminaría rumbo a la dictadura o a la descomposición social. ${ }^{26}$

El propio Venustiano Carranza - proseguían - habia iniciado el levantamiento contra la usurpación huertista con el objetivo de reivindicar a la Constitución de 1857 y reiteradamente había expresado su respeto hacia los derechos del hombre, particularmente hacia la propiedad privada. El proyecto de reformas que presentó al constituyente había sido elaborado con esa orientación. ${ }^{27}$ Parece claro que al recordar al presidente que sus concepciones no habían quedado plasmadas en el texto constitucional, pretendian presionarlo para evitar la posible aplicación de las medidas adoptadas por la mayoría jacobina.

Después de esa introducción, el documento prosigue de acuerdo con las partes del artículo en debate. En primer lugar se referían al problema del subsuelo, señalando que en toda la legislación independiente previa no existía la posesión del Estado sobre/el subsuelo. Con su inclusión en el texto del 17, se atentaba contra el equilibrio de los poderes que debía privar en un sistema republicano, pues se concentraba una enorme suma de facultades en el Ejecutivo. ${ }^{28}$

El socialismo, continuaban, se propone la supresión de la propiedad privada, del matrimonio monogámico y de la ley de la libre competencia, pero eso no puede ocurrir, ya que atenta contra las desigualdades naturales y contra las fuerzas creadoras del individuo. ${ }^{29}$

Con el artículo 27 se creaba, según esta interpretación, un socialismo sui géneris, puesto que:

Con esta suma de facultades, con esta amplia acción del poder Público, es evidente que todo queda en sus manos, es claro que se funda un estadismo, un socialismo sui géneris, que sigue reconociendo la propiedad individual, pero de un dia, de un instante, movediza, sin límites, sin sentido jurídico, y entonces es inútil la división de poderes, la suma de facultades atribuída a cada uno de ellos, las correlaciones de

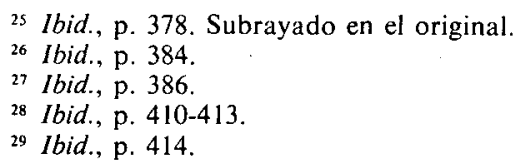


esos poderes, la implantación del poder judicial, especialmente de la Suprema Corte de Justicia, y del recurso de amparo, ya que no hay derechos que amparar, que proteger. ${ }^{30}$

Con ese socialismo, se borraba la concepción del Estado fundado en la idea del derecho como órgano protector de la libertad humana y en su lugar quedaba implantado como institución de gobierno despótico, omnipotente y soberano. ${ }^{31}$

Por lo que toca a la retroactividad implícita en las disposiciones del artículo 27 , los industriales sostenian que lo que anteriormente había sido constituido como propiedad privada, había salido del dominio de la nación, la que únicamente había conservado sobre ella la soberanía territorial que ejercía sobre todas las partes constitutivas de su territorio. ${ }^{32}$

La expropiación por causa de utilidad pública mediante indemnización configurada en el texto, era una de las cuestiones que más preocupaba a los industriales. La calificaron de medida extrema que, en todo caso debía compensarse real, justa y oportunamente, es decir, previamente, con el valor comercial y en metálico. Por lo demás, diferían en lo que había de entenderse como causa de utilidad pública. Según ellos, la utilidad pública era "el provecho o conveniencia procomunal necesarios externa y directamente, para la existencia y desarrollo indispensable de las fuerzas vitales de la misma colectividad", que evidentemente estaban en el individualismo. ${ }^{33}$ De esa concepción se seguía que la expropiación, por "provecho externo", de ferrocarriles, telégrafos, puertos, servicios militares, etc., estaba plenamente justificada, mientras que aquella que afectara otras actividades no lo estaba. ${ }^{34}$ Esta es una de las ideas claves del documento, pues en otros términos significaba la aceptación de que el Estado podía intervenir en la economía, siempre y cuando tal intervención se limitara a desarrollar la infraestructura necesaria para hacer más rentable la inversión privada y dejara que los empresarios privados se ocuparan de los sectores más dinámicos de la economía. En suma, el Estado debía concretarse a dar facilidades para el proceso de acumulación de capital.

Por tanto, afirmaban, se puede limitar el derecho de propiedad, pero no destruirlo, pues no hay interés general por grande que sea que deba prevalecer sobre un derecho. En el texto en debate, la regla general era la limitación y la excepción el derecho. En la práctica, concluian, se destruía el derecho a la propiedad privada y se condenaba a muerte a la industria. ${ }^{35}$

En lo tocante a las restricciones impuestas al capital extranjero para ser invertido en México, señalaban que eran ilegales a la luz del derecho internacional, ya que, finalmente, los gobiernos extranjeros no acatarian la renuncia de nacionalidad y seguirian teniendo como deber ineludible la protección de sus ciudadanos. Además, hacian notar que el $60 \%$ de los negocios mineros estaba en poder de compañías extranjeras que, gracias a sus grandes capitales, podían explotar regiones que de otra manera quedarian abandonadas, con el consiguiente desempleo y des-

30 Ibid., p. 415.

31 Ibid., p. 418.

32 Ibid., p. 419.

33 Ibid., p. 423.

34 Ibid, p. 426.

35 Ibid., p. 430. 
censo del nivel de vida de los trabajadores ocupados en ellas. Por otro lado, reiteraban que

... En México, por desgracia, [...]; no hay capital suficiente para desarrollar esta especie de negocios y los capitalistas nacionales, tímidos por principio y por costumbre, no se atreven a aventurarse en negocios para ellos desconocidos y cuyos resultados son inciertos. Por penoso que sea confesarlo, se ve que todas las grandes empresas del país se han llevado a cabo por extranjeros y con capitales extranjeros. ${ }^{36}$

Este pasaje es ilustrativo del pensamiento de una parte considerable de los capitalistas nacionales, que ante las dificultades para desarrollarse como clase autónoma, preferían las bondades de la dependencia del capital transnacional y las migajas que esa relación les aseguraba. $\mathrm{Su}$ "espíritu de empresa" sólo llegaba a ese punto.

Por último, al tocar las prohibiciones a las sociedades comerciales por acciones para adquirir fincas rústicas, repetían el argumento de que sólo grandes capitales podían hacer grandes negocios, y que esas empresas requerian infraestructura territorial suficiente para su actividad, que, finalmente, sería benéfica para el pais. ${ }^{37}$

Al final del dictamen reiteraban su disposición inicial de contribuir a la reconstrucción del pais y en seguida hacian las siguientes proposiciones al Congreso:

Primera. Del estudio que antecede, se desprende la imperiosa necesidad de que se modifique el contenido del artículo 27 Constitucional, de acuerdo con los intereses morales, materiales, económicos y sociales, que representan las industrias del país, mediante las reformas que lógicamente exige el precepto, en vista de las consideraciones que encierra dicho estudio.

Segunda. Solicítese del C. Presidente de la República, por conducto de la Secretaría de Industria y Comercio, tome en consideración el estudio que antecede, para los fines que se indican en la primera de estas proposiciones. ${ }^{38}$

El dictamen fue presentado el día 15 de diciembre. Junto con este documento se habían discutido otros, entre los que se encontraba la propuesta del delegado Manuel A. Chávez para que se apoyara el proyecto de Ley Orgánica del Artículo 27 presentado por el gobernador de Veracruz y cercano colaborador de Carranza, Cándido Aguilar. Esa proposición fue rechazada por el Congreso, puesto que en lo fundamental se adecuaba al contenido del artículo, que como hemos visto, no era del gusto de los industriales. ${ }^{39}$

Finalmente, el 21 de diciembre, el Congreso aprobó una modificación al dictamen antes analizado, para hacerlo más agresivo, quedando de la siguiente manera:

Unica. El Primer Congreso Nacional de Industriales recomienda la revisión y reforma del artículo 27 constitucional, cuyo texto lesiona

\footnotetext{
36 Ibid., p. 434.

37 Ibid., p. 435.

38 Ibid., p. 437.

39 Ibid., p. 444-447?
} 
profundamente los derechos e intereses de la industria porque desconoce el derecho de propiedad privada y se opone al desarrollo de aquélla. ${ }^{40}$

Es claro que los sectores mineros y petroleros no estaban dispuestos, a pesar de sus protestas en contrario, a marchar junto al gobierno revolucionario, sino a condición de cambios constitucionales que garantizaran sus inversiones.

Dictamen sobre el artículo 123. La comisión designada para el estudio y dictamen del artículo 123 difería de la anterior en cuanto a su composición, ya que estaba dominada por los representantes de la industria textil y manufacturera.

Estos delegados, en primer lugar, destacaban la amplitud sin precedente del artículo mencionado, ya que según su punto de vista débía limitarse a hacer algunos señalamientos generales y dejar para un Código del Trabajo las cuestiones particulares. Al igual que en el caso del artículó 123, se declaraban coincidentes con la postura previa de Carranza plasmada en el Proyecto de Reformas entregado al constituyente. ${ }^{41}$

Pasaban a señalar que la reglamentación del texto constitucional por un código específico era una facultad constituyente que no debía delegarse en las legislaturas locales, como lo establecía el artículo de marras, sino que en una república federativa debia tener alcance general la aplicación de sus preceptos.

Entre las desventajas de dejar al arbitrio local la elaboración de códigos del trabajo, señalaban:

Si son de interés nacional el trabajo y la industria, lo que nadie puede negar, la expedición de leyes orgánicas del trabajo por todos los poderes legislativos de las entidades federativas traerá como consecuencia ineludible, tal diversidad, tan grande antinomia en sus prescripciones, que con motivo de legislar sobre Trabajo se buscaría la preponderancia de una lucha de intereses de Estado a Estado, proscrita por el buen sentido y por los verdaderos intereses nacionales, porque fácilmente se comprenden los celos $\mathrm{y}$ antagonismos entre unos y otros Estados, la ambición desmedida por parte de los más poderosos, las intrigas de los más débiles, causando todo ello tal confusión de disposiciones legales que harían difícil y obstruccionaría el cauce y el camino que debiera seguir en su evolución el progreso industrial. ${ }^{42}$

En realidad temian, justamente, que algunos poderes regionales de orientación radical inclinaran la balanza de las relaciones obreropatronales en favor de los primeros, como ya había ocurrido en Sonora, Michoacán y Yucatán, en donde se promulgaron reglamentos del artículo 123 que recogían los postulados más radicales del mismo.

Por lo demás, es claro que suponían, a partir de sus coincidencias suficientemente corroboradas, que sería más fácil negociar con el presidente Carranza que con varias decenas de gobernantes locales. Su conclusión respecto a este tema era contundente. Decían:

40 Ibid., p. 573.

41 Ibid., p. 448-451.

42 Jbid., p. 450. 
Por lo anteriormente expuesto, la Comisión opina en idéntico sentido que el actual C. Presidente de la República, a propósito de que la legislación del trabajo, para obtener unidad y aplicación general en toda la República, debiera emanar del Congreso de la Unión y tener en consecuencia el carácter de federal. ${ }^{43}$

Sin embargo, se cuidaban de aclarar que este planteamiento no tenía fin político alguno, y mucho menos debía interpretarse como un afán opositor al gobierno o como señal de animadversión a la clase obrera, ya que sus ambiciones se reducían únicamente a que

.. las nociones de justicia y de equidad presidan las constantes relaciones del capital y del trabajo, para colaborar a la paz social y a la tranquilidad pública que anhela el Primer Congreso Nacional de Industriales, como corporación... ${ }^{44}$

En cuanto a la jornada máxima de trabajo, que el artículo 123 fijaba en ocho horas, señalaban que era una utopía predicada por obreros socialistas y que provocaria la disminución de la productividad nacional. Les parecía conveniente que en la República mexicana la jornada máxima de trabajo fuera de diez horas para las industrias generales, como la textil, subsistiendo la de ocho en la minería y otras industrias que exigieran del obrero adulto mayor fuerza, tensión y gasto muscular. ${ }^{45}$

Esa era una defensa de principio de la plusvalia absoluta, es decir, de aquélla generada por el alargamiento de la jornada de trabajo, pero también era un reconocimiento de que el capitalismo mexicano no estaba lo suficientemente desarrollado para hacer posible que la tasa de explotación aumentara por la vía de extraer una mayor plusvalia relativa, es decir, por la vía de reducir el tiempo de trabajo socialmente necesario para la producción de las mercancías de subsistencia.

Para ello se requeriría un aumento de la productividad que los industriales no contemplaban en ese momento como una posibilidad a corto plazo. ${ }^{46}$

Mantener la jornada de ocho horas tendría, según la línea de razonamiento empresarial, otras repercusiones. Con menos horas de trabajo, el obrero tendría mucho tiempo libre, lo que podría llevarlo a la disipación y tal vez a adquirir malos hábitos. ${ }^{47}$

Por otra parte, ya que el salario estaba tan ligado al tiempo de trabajo, si el Estado fijaba la duración de la jornada debía fijar también un salario que "pudiera equilibrar y armonizar en justicia los intereses del capital y del trabajo, dado que la reducción de las horas de labor disminuye la productividad del obrero y forzosamente del beneficio que obtiene cuando su salario es a destajo". ${ }^{48}$

Un argumento más para rechazar la jornada de trabajo de ocho horas era que, según ellos, la experiencia había mostrado que la salud del obrero textil no se alteraba con el trabajo de diez horas.

43 Ibid., p. 451.

44 Ibid, p. 451.

4 Ibid, p. 452.

${ }^{46}$ Carlos Marx, El Capital, t. I, vol. 2, "El proceso de producción del capital", Ed. de Pedro Scaron, México, Siglo XXI, 9a. ed., 1981, véase cap. X y XV.

${ }^{47}$ Reseña y Memorias..., p. 452.

48 Ibid. 
En consecuencia - afirmaban-, la reducción de la jornada a ocho horas traerá resultados perjudiciales a todos; al obrero se le limita su actividad para ganar mayor salario, y para el capital esa disminución le significa la limitación de productividad en sus fábricas, aumento del precio de producción y situación desventajosa de competencia con los mercados extranjeros, en los que no existe aceptada la jornada corta de ocho horas. Para el consumidor representa un aumento ineludible del precio del producto, supuesto que el mismo costo en gastos generales y el salario y los impuestos, deberán repartirse entre menor producción. ${ }^{49}$

La participación de utilidades dispuesta en el texto constitucional también fue severamente rechazada por la Comisión, ya que alejaria los capitales del país y provocaría la abdicación de los derechos del empresario a disponer de los productos de su capital y espíritu de empresa, quedando sometido a autoridades que con tal de granjearse popularidad no tendrían inconveniente en arruinarlos.

En seguida hacían un ataque a lo que según su particular apreciación eran los puntos de vista del socialismo.

Que la idea de hacer partícipes a los obreros en los beneficios de la empresa, fue formulada por Leclaire y en los últimos tiempos por Carlos Marx, quien exageró de tal manera el valor que en la producción industrial tiene la intervención del obrero, que llegó hasta subalternar el capital a la mano de obra y a olvidar la importancia que tienen en la producción el Director con su capacidad técnica, el empresario con su prestigio y las fluctuaciones y fenómenos que en el ambiente económico sufren inexorablemente los productos de la gran industria, debido a la pluralidad de factores que se emplean en la producción..$^{s 0}$

Finalmente proponian como medio alternativo para mejorar la condición del obrero establecer el'sistema del seguro obligatorio, que abarcara dos especies, el seguro en caso de muerte y el seguro en caso de accidente. En ambos sería responsabilidad del patrón sólo si el incidente se debiera al mal estado de máquinas o aparatos, o bien a defectoś de instalación. También proponían un mecanismo operatorio del mismo; en sus palabras:

El seguro obligatorio que nos permitimos sugerir estaría siempre bajo la vigilancia e intervención del Gobierno, constituyéndose el capital con las aportaciones que los patrones, y en su caso los obreros, harían anualmente; los primeros de uno, dos a cinco por millar de la suma total que alcanzare el precio de los salarios pagados. ${ }^{51}$

Después de todas esas reflexiones, ponian a la consideración del Congreso las proposiciones siguientes:

Primera. Es una aspiración o un desiderátum del Primer Congreso

${ }^{49}$ Ibid., p. 453

${ }^{50} \mathrm{Ibid}$, p. 454. Lo que se atribuye a Marx aqui obviamente es incorrecto. Marx no proponia hacer a los obreros participes de los beneficios de la empresa capitalista, sino la transformación de la propiedad privada en social, es decir, la destrucción de la propiedad privada. Véase Carlos Marx, El Capital, op. cit., t. I, vol. 3, cap. XXIV, acápite 7.

s1 Reseña y Memorias..., p. 455. 
Nacional de Industriales, la unidad de la legislación obrera, la federalización de la industria nacional, por medio de la expedición de un Código Federal del Trabajo.

Segunda. Solicítese muy respetuosamente del C. Presidente de la República, por conducto de la Secretaría de Industria y Comercio, que al proyectar o al iniciar las leyes industriales, sean oídos este Congreso Industrial, por medio de la Comisión Permanente que haya de nombrar, y los demás Centros y Confederaciones de Industriales, que tengan existencia legal en la República. ${ }^{52}$

Este dictamen fue presentado el 5 de diciembre a discusión, y como en el caso del artículo 27, la Asamblea modificó el 19 del mismo mes las propuestas de resoluciones en un sentido más radical. En realidad sólo incorporaron un primer punto, y recorrieron los dos ya citados a los lugares segundo y tercero. El punto añadido decía asi:

I. El Primer Congreso Nacional de Industriales considera necesario para la vida de la industria en el país que se reforme el artículo 123 constitucional dentro del criterio que informa este dictamen y los estudios a que se refiere la proposición final del mismo. ${ }^{53}$

A pesar de las críticas al artículo 123, este sector de los industriales, compuesto de representantes de la industria textil e industrias varias, se mostraba más dispuesto a colaborar con el Estado, sobre todo en aspectos concretos, como la creación del seguro obligatorio. Esta actitud se explica en tanto era más débil que el primer grupo y no había sido afectado en la misma intensidad por las nuevas disposiciones constitucionales. A pesar de eso, su colaboración se daría sólo si el gobierno accedia a aceptar sus proposiciones.

Otras resoluciones. Entre las demás resoluciones que tomó el Congreso, destacan aquellas promovidas por los representantes manufactureros que chocaban con la posición liberal a ultranza sostenida por Pani. Ellas eran las que solicitaban la derogación de los decretos que eximian de derechos de importación a telas de algodón similares a las que se producían en el país, la elevación de cuotas arancelarias sobre fósforos, cerillos y velas del extranjero, y el rechazo al establecimiento de una "zona libre" en la frontera.

Los mineros, por su parte, solicitaban la exención temporal de derechos de exportación sobre el zinc, la modificación del monto y aplicación del impuesto minero, y la derogación del decreto que restringía la exportación de minerales. ${ }^{54}$

En resumen, el Congreso no tuvo los resultados previstos por el gobierno, ya que la negociación propuesta por el mismo para trabajar conjuntamente en la reconstrucción de la economía nacional, no fue aceptada por los industriales. Los ataques del Congreso a la nueva Constitución fueron el síntoma más claro de ello y de que no estaban dispuestos a constituirse en apoyo político del régimen. Los empresarios en su conjunto desconfiaban del nuevo estado de cosas, y como hemos visto antes, se manifestaba también en su renuencia a invertir. Sin embargo, hubo un logro. La Confederación de Cámaras Industriales de los Estados Unidos Mexicanos fue constituida en septiembre de

52 Ibid, p. 456.

${ }^{53}$ Ibid., p. 573-574.

s4 Ibid. p. 83. 
1918, siendo electo Adolfo Prieto como su primer presidente. Prieto había representado en el Congreso a los textileros, además de ser el gerente de la Fundidora de Fierro y Acero de Monterrey. ${ }^{55}$

\section{Conclusiones}

De los dos objetivos centrales del gobierno carrancista frente a los empresarios nacionales: el de obtener su colaboración y apoyo en el proyecto de reconstrucción económica y el de promover su organización, sólo el segundo pudo concretarse en el primer intento de acercar a las dos partes. Las razones que influyeron son varias. En primer lugar el propio Estado de la Revolución no estaba estructurado definitivamente y no comenzaba todavia a poner en práctica un proyecto modernizador del capitalismo. En efecto, un programa de esa naturaleza se puso en vigor a la llegada de los sonorenses al poder, es decir, a partir de 1920. Además, algunos sectores de la burguesía habian sido afectados por la lucha armada y, sobre todo, una gran parte de ellos se sentía excluida del poder político. Otro factor fue la desconfianza hacia un movimiento protagonizado por campesinos y obreros, aunque hoy es claro que no tuvieron injerencia en la dirección del mismo. Finalmente, las disposiciones reformistas contenidas en la Constitución de 1917 les parecían atentatorias de derechos que consideraban naturales.

Sin embargo, en el terreno de la organización empresarial sí se obtuvieron avances, con la creación de la CONCAMIN y la CONCANACO, que de esa manera se convertían en interlocutoras del Estado, tanto para casos de negociación como de conflicto. Esto se corresponde también con la estructuración nacional del movimiento obrero, al ser creada la CROM (1918).

En el terreno de las ideas es bastante claro que un gran número de las tesis manejadas en el congreso de industriales permanecieron en el discurso empresarial en las décadas siguientes. En otras palabras, esto significa que este es un momento decisivo en la conformación de la burguesía como una clase con un proyecto propio de desarrollo nacional.

Finalmente, es necesario resaltar que en esta etapa se expresaron ya las propias divergencias existentes entre los distintos sectores de la burguesía, pues era distinta la actitud de enfrentamiento directo con el gobierno de los petroleros y mineros a la actitud de oposición moderada de los manufactureros. Esto se haría más claro con el tiempo: los petroleros se alejarian de la CONCAMIN; los empresarios regiomontanos, más ligados al capital extranjero, promoverían la formación de la Confederación Patronal Mexicana (COPARMEX), y solamente los manufactureros colaborarian con el Estado de la Revolución.

ss Maria Cristina Puga Espinoza, Los industriales y la revolución mexicana, op. cit., p. 49 . 